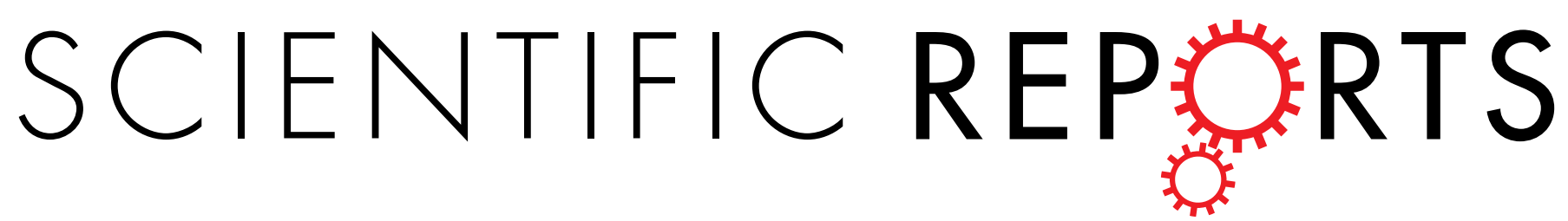

\title{
OPEN Erratum: Simultaneous excitation and emission enhancements in upconversion luminescence using plasmonic double-resonant gold nanorods
}

\section{Xin Liu \& Dang Yuan Lei}

Scientific Reports 5:15235; doi: 10.1038/srep15235; published online 15 October 2015; updated on 18 December 2015

In the original version of this Article, Dang Yuan Lei was incorrectly listed as being affiliated with 'Key Lab of Advanced Transducers and Intelligent Control System of Ministry of Education and Shanxi Province, College of Physics and Optoelectronics, Taiyuan University of Technology, Taiyuan 030024, China'.

In addition, Dang Yuan Lei should only be affiliated with 'Department of Applied Physics, The Hong Kong Polytechnic University, Hong Kong, China'.

These errors have been corrected in both the HTML and PDF versions of the Article.

(c) (i) This work is licensed under a Creative Commons Attribution 4.0 International License. The images or other third party material in this article are included in the article's Creative Commons license, unless indicated otherwise in the credit line; if the material is not included under the Creative Commons license, users will need to obtain permission from the license holder to reproduce the material. To view a copy of this license, visit http://creativecommons.org/licenses/by/4.0/ 